\title{
Article \\ Evaluation of an Additional Generator on the Economic Effect Based on a Load Sharing Optimization of Medium-Speed/High-Speed Diesel Generators in a Microgrid
}

\author{
Shuhei Yamano ${ }^{1, *}$ and Atsushi Akisawa ${ }^{2}$ \\ 1 Graduate School of Bio-Applications and Systems Engineering, \\ Tokyo University of Agriculture and Technology, 2-24-16, Naka-cho, Koganei-shi 184-8588, Tokyo, Japan \\ 2 Institute of Engineering, Tokyo University of Agriculture and Technology, Fuchu 184-8588, Tokyo, Japan; \\ akisawa@cc.tuat.ac.jp \\ * Correspondence: res.yamano@gmail.com; Tel.: +81-(0)80-8889-2963
}

check for updates

Citation: Yamano, S.; Akisawa, A.

Evaluation of an Additional

Generator on the Economic Effect

Based on a Load Sharing

Optimization of Medium-Speed/

High-Speed Diesel Generators in

a Microgrid. Energies 2022, 15, 1007.

https://doi.org/10.3390/en15031007

Academic Editors: Ferdinanda Ponci and Constantine D. Rakopoulos

Received: 25 November 2021

Accepted: 26 January 2022

Published: 29 January 2022

Publisher's Note: MDPI stays neutral with regard to jurisdictional claims in published maps and institutional affiliations.

Copyright: (C) 2022 by the authors. Licensee MDPI, Basel, Switzerland. This article is an open access article distributed under the terms and conditions of the Creative Commons Attribution (CC BY) license (https:// creativecommons.org/licenses/by/ $4.0 /)$.

\begin{abstract}
This study investigates the additional installation of a high-speed diesel generator to independent microgrids $(\mathrm{MG})$ such as remote islands where relatively efficient medium-speed diesel generators (DGs) are mainly used. While small-sized and lightweight, high-speed DGs are not widely spread for continuous usage because their efficiency is lower than that of the medium-speed DGs. The objective of this study is to evaluate the performance of the new method of load sharing optimization to improve the economy by interconnecting a high-speed DG to an independent MG where the medium-speed DGs are operated. The study investigates the effect of operation cost reduction by installing the new load sharing method of operation following the load sharing pattern derived by the mixed-integer programming. As a result of this study, there was some effect to installing a high-speed DG operated by the conventional method. In addition, by adding the new method of load sharing with optimization, the economic effect became even higher.
\end{abstract}

Keywords: microgrid; load sharing; high-speed DG; medium-speed DG; mixed-integer programming

\section{Introduction}

In a microgrid (MG) whose scale is generally small, diesel generators (DG) tend to be used [1], and petroleum fuel is transferred to them. Their rated generator efficiencies are lower than large-scale power generators such as a gas turbine combined cycle (GTCC) used in large-scale grids.

In addition, the MG needs to ensure a stable power supply with its limited power generators in preparation for unexpected equipment outages and sudden load increases. Therefore, the load factor of each unit is determined so that the total rated capacity for generators that are in operation shall be larger than the actual demand with a secured margin. Power generators of an internal combustion engine generally take a higher fuel cost because the efficiency becomes worse to operate in the range of low load factors.

Sasaki et al. surveyed the power supply business at an MG in Myanmar and mentioned that improving the fuel cost is also an important issue from the viewpoint of the continuity of the existing generator business and for new development in non-electrified areas [2].

A large improvement effect on business profits can be expected if the operating efficiency of the entire power plant is improved by changing the operating method, for example, since the fuel costs dominate the operating costs of power plants.

Dulau et al. [3], He et al. [4], and Togawa et al. [5] investigated the optimization to minimize the cost of MG, considering renewable energy and waste heat utilization based on the mixed-integer programming method (MIP). An integer programming problem is a mathematical optimization or feasibility program in which some or all of the variables are restricted to be integers. It can model complex planning and control problems involving 
both continuous and discrete decisions. MIP problems involve the optimization of a linear objective function, subject to linear equality and inequality constraints. Some or all of the variables are required to be an integer. Kannengießer et al. applied a mixed-integer linear programming method (MILP) to reduce the cost by modeling in two steps with an accurate scaling [6]. Gildenhuy et al. have developed a multi-objective optimization model using a hybrid function of a genetic algorithm to analyze a multi-MG system and minimize not only the operating costs but also $\mathrm{CO}_{2}$ emissions [7]. Ito et al. considered partial loads with optimizations of equipment configuration [8]. Furthermore, Chiba et al. studied a method in which operational parameters are sequentially optimized by a genetic algorithm [9]. Pang et al. apply a genetic algorithm (GA) and an MILP model to solve a two-step optimization consisting of equipment planning by GA and demand selection by MILP [10]. However, the conditions of these MGs are not completely independent; power interchange with other grids is expected to meet the MG's power demand, therefore, the power generators can be operated on high load factors. Ghiasi et al. investigate the optimization algorithm on an MG that considers the economic costs and $\mathrm{CO}_{2}$ emissions with a model that can limit the power interchange with the upper grid by applying the multi-objective differential evolution [11].

This study targets generators located on remote islands as a highly independent MG. Therefore, compared to the above investigations, this study is different in that the demand shall be satisfied with only a limited number of units and the capacity of the generators installed in the MGs.

Regarding the load sharing method to reduce the operating costs of the power plant, Koguma et al. applied the approximation method which determined non-linear variables and solved the model as a linear programming problem [12]. Shinji et al. investigated an optimization considering the partial load of the distributed power source [13]. However, the generator efficiency was assumed as constant in these investigations, although it is fluctuated depending on the load factor. Therefore, the situation where the superiority of efficiency can be switched depending on the load factor was not considered.

Watanabe et al. have developed a simulator for operating multiple power plants with linear programming that approximates the piecewise linear function of fuel consumption, where fuel consumption characteristics differ depending on the power generator [14]. In this method and the equi-incremental fuel cost method [15], the fuel efficiency curve is close to a straight line in the high range on the load factor of the power generators, so that a piecewise linear approximation can be expected to be represented with sufficient accuracy. However, such a method is not realistic to such situations presented in this study since so many segments are necessary to approximate the fuel consumption curve with high accuracy even in the range of low load factors.

As mentioned above, the independent MG power generators are operated in the range of low load factors to secure the reserve rate. Therefore, this study proposes a method to optimize the load sharing of each unit by the mixed-integer linear programming with highprecision approximation, including the range of low load factors on the fuel consumption characteristics for the generators to which linear approximation is not applicable [16].

In addition, the arrangement of generator resources is also a very important issue for such independent MGs that cannot receive backup power supply from other grids. Installing additional power generators is one of the measures to strengthen generator resources in MGs. Kojima et al. investigated combining renewable energy and storage batteries [17]. Dulaua et al. studied how to optimize operating costs in a hybrid model of renewable energy and storage batteries [3]. Lavrik et al. studied how to optimize the size of a hybrid energy system with load-shifting in remote areas of Sakhalin Island [18]. Demonstration tests have also been conducted to examine renewable energy in the Oki Islands of Japan [19]. A demonstration project of wind generators and their management system has been carried out on a remote island, and a financing scheme for installation has also been examined [20]. 
It should be noted that there are still some concerns about the installation of variable renewable energy to provide a stable supply of electric power to a single system. These concerns are about the deterioration of power quality to dominate power supply systems with a high ratio since such power supply devices which are photovoltaic generators and storage batteries do not have inertial force [21]. In addition, storage batteries are more expensive and have a shorter life cycle compared to conventional generator technology [22,23]. It also requires a higher cost to replace batteries every several years including the transport cost to remote areas where such independent MGs are located.

There are two types of reciprocating engines generally used for generators in such scales of MGs in this study. Types such as medium-speed or high-speed are specified in terms of rotation speed. There are differences in their characteristics, such as generator efficiency and maintenance unit price [24]. Yamano et al. investigated the economic effect for the operation method considering their characteristics from the viewpoint of their combination [25].

As a realistic measure to strengthen the generator resources, this study evaluates adding one high-speed DG, which is a rotating one that can stably supply electric power with lower installation costs. It is assumed that the additional high-speed DG unit will be combined with the existing multiple units of the medium-speed DG for regular operation.

As described above, the objective of this study is to evaluate the possibility to reduce the operation cost of the power plant by adding a new method of load sharing optimization and a DG. The key points are below:

- Evaluation of the economic effects of the mixed operation of medium- and high-speed reciprocating engine generators;

- Establishment of a method to accurately approximate non-linear fuel consumption curves from the low range to the high range and optimize them with MIP;

- The proposal of a method to reduce the operating costs of independent MGs that is effective even when the balance between the generator unit configuration and demand changes.

- The proposal of a method to strengthen the resilience of independent MG power plants that cannot receive power support from other sources.

\section{Operation of the Diesel Generators in Microgrid}

2.1. Assumed Microgrid Conditions

The small-scale independent MGs assumed in this study shall operate under the following conditions:

- $\quad$ Located in remote areas such as remote islands;

- The power demand is dominated by consumer use, and large-scale consumers such as the manufacturing industry shall not be there;

- Not connected to other grids, and power is not supplied to nor received from outside;

- Multiple medium-speed generators of several hundred to $2000 \mathrm{~kW}$ supply power are used;

- The operation of the generator is controlled to minimize the sum of fuel and maintenance costs;

- The unplanned withdrawal due to unit failure, etc., shall be taken into account for stable power supply.

\subsection{Conventional Concept of the Diesel Generators Operation}

It is not uncommon to install generators with different capacities in stages as demand increases gradually. Therefore, this study assumes a situation where relatively large and medium-sized generators are combined.

In a small-scale independent MG, the medium-speed DG is superior because the equipment planning prioritizes the generator's efficiency. In many cases, the start and stop of each unit are performed by an operator or a timer. 
The actual load factor determination varies depending on the configuration of the power generators. The load factors for each unit are sometimes determined proportionally to the rated capacity. This study assumes a so-called "baseload operation", in which a unit with a large inertial force is loaded a little more than the others. Hence, it is assumed that one large-capacity generator is operated with a load factor $10 \%$ higher than the other units, and the others are evenly sharing the rest of the load with the same load factor.

\subsection{Proposal of New Generator Operation Method}

This study proposes a new operation method to minimize the annual operating cost. This method optimizes the load sharing according to the fuel consumption characteristics of the generators. Instead of the conventional method, load factors for each unit are determined based on their rated capacities. In addition, this method is examined to derive the optimization of a load sharing for a system that mixes the medium-speed and the high-speed DGs with different fuel and maintenance cost characteristics. It is expected to improve the economy not only in the case of multiple medium-speed DGs but also in the case of adding one high-speed DG.

In addition, such an optimization method should also be used for the actual operation of DG units. Therefore, at the stage of determination of the unit configuration, a matrix that optimizes the operation units and their load factors corresponding to each demand value in units of $1 \mathrm{kWh}$ unit from the minimum to the maximum is created. Then, at the actual operation stage, whether each unit should be run or stopped and the load factors among the units are determined according to the matrix corresponding to the demand value.

When the demand value is given to the system controller by the signal input cycle, each unit shall be controlled to operate with the optimum load factor determined in the matrix. The optimal combination of the operation units is always controlled by the matrix. Thus, each result of the optimization corresponding to a demand value shall be used for actual operation on this method. This is also the advantage of this method compared to the conventional optimization method, whose operation plan is already fixed at the planning stage.

Changes in the unit configuration among the generators in operation without interrupting the power supply are routinely carried out at power plants. The generators whose capacities are similar to the ones in this study can take a load in tens of seconds or a minute from the start. It is conceivable that these DGs can sufficiently follow the load fluctuation in the MG that has conditions similar to those in this study.

\subsection{Characteristics of Medium and High-Speed Diesel Generators}

The usage of generators in this study shall be for a regular power supply. In terms of types for generators in this study, the medium-speed DGs tend to be preferentially selected for continuous use due to higher efficiency [16]. It is generally recognized that the high-speed DGs are less used than the medium-speed DGs because their rated generator efficiency is lower than that of the medium-speed DGs. In addition, the maintenance cost for the high-speed DGs is generally more expensive than that of the medium-speed DGs because their rotation speed is higher and the replacement cycle for the parts related to pistons and cylinders is shorter. On the other hand, they have advantages such as a smaller installation area and an easy installation at a reasonable cost due to the compact design.

Table 1 shows the representative values of the generator efficiency for the mediumspeed and the high-speed DGs at each load factor $[16,26,27]$. The approximate equation for the generator efficiency $g E f(x)$ shown in Figure 1 is determined in the following Equations (1) and (2), where $x$ is the load factor. Here, $\eta$ is an empirical value that takes into account the actual variance in mechanical performance for each unit. The minimum operating load factor is assumed to be $25 \%$.

Medium-speed DG(s):

$$
g E f(x)=0.2014 \times\left(\frac{x}{100}\right)^{3}-0.5934 \times\left(\frac{x}{100}\right)^{2}+0.6143 \times \frac{x}{100}+0.1856-\eta
$$


High-speed DG:

$$
g E f(x)=-0.4502 \times\left(\frac{x}{100}\right)^{4}+1.6633 \times\left(\frac{x}{100}\right)^{3}-2.2825 \times\left(\frac{x}{100}\right)^{2}+1.4166 \times \frac{x}{100}+0.0288
$$

Table 1. Representative values of efficiency of DGs.

\begin{tabular}{ccc}
\hline Load Factor & Medium-Speed DG & High-Speed DG \\
\hline $100 \%$ & $40.8 \%$ & $37.6 \%$ \\
$75 \%$ & $39.8 \%$ & $36.7 \%$ \\
$50 \%$ & $37.0 \%$ & $34.6 \%$ \\
$25 \%$ & $30.5 \%$ & $26.5 \%$ \\
\hline
\end{tabular}

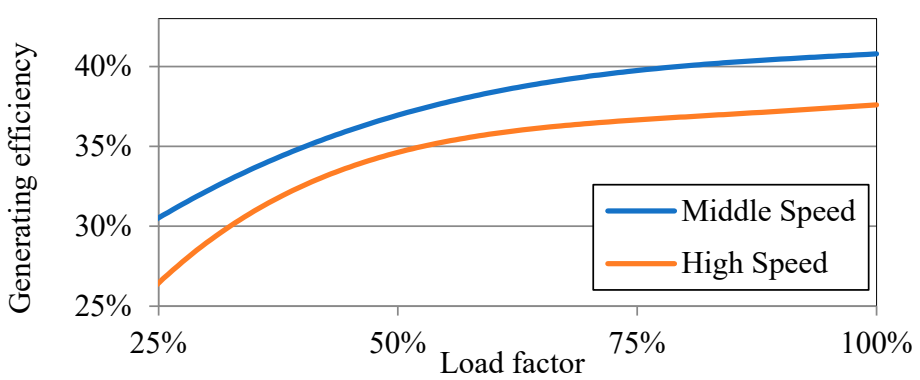

Figure 1. The performance curve of the diesel generators.

\section{Optimization Model for Generator Operation}

\subsection{Features of Modeling}

The feature of the modeling in this study is the approximation of the fuel consumption characteristics even in the range of low load factors with high accuracy, which is difficult to approximate linearly, and optimization of the load factors for each unit from the economic viewpoint using the MIP.

To optimize the load sharing by the MIP in this study, the values of output for each unit are discretized by the load factor in units of 1 percent, and the selection of optimal output value for each unit is expressed by binary variables. Since it is not an optimization for the non-linear function, this solving method has the advantages of wide applicability and ensured optimality. As the method is to select the discrete load factor for each unit, the output values are combined flexibly to satisfy the demand. Furthermore, as the flexibility is higher than that of the conventional operation method, a solution that has a higher economic effect is expected.

In addition, this study also considers unplanned withdrawals of a unit from the viewpoint of the resilient response of MG. A power failure may occur in the system when an unplanned outage happens in such an independent MG without backup power supplies from other grids. Therefore, some of the constraints are required in terms of the total rated output of generators in operation, so that the demand can be satisfied by the total output of the remaining units to ensure the power supply reliability even when the unit with the maximum capacity is withdrawn by any trouble. The combined units are determined so that the total rated capacity always secures a margin beyond the demand equivalent to one maximum rated capacity or more.

This study assumes the number of unplanned outages as one since the diesel generator's reliability is high enough.

\subsection{Objective Function}

Although the economy of the power supply business depends on the income from selling electricity and the cost, this study focuses on the minimization of the annual variable cost for evaluating the economy of the MG's power plant. The annual variable costs consist of the fuel costs, equipment maintenance cost, and labor cost required for the operation 
of the power plant. Personnel costs shall be excluded because there is no difference in the proposed method in this study. The annual variable cost can be calculated by determining the operating model for each unit [28]. Therefore, along with the change of the unit configuration in operation, this study compares the operating costs of the conventional and the proposed method and evaluates the effect of an additional DG.

The objective function is expressed as follows. The load sharing is determined to minimize the annual variable costs shown in Equation (3) in both the conventional and the proposed methods. The annual variable cost is the sum of the annual fuel cost and maintenance cost:

$$
c O p=c F l+c M t
$$

The values of demand are considered for each hour on weekdays, Saturdays, and holidays $(w)$ in each month $(m)$, and the annual electricity demand for $8760 \mathrm{~h}$ constitutes 864 patterns ( $24 \mathrm{~h}, 12$ months, 3 day-types). The output of each unit to satisfy the demand becomes a variable in the model:

$$
g P w_{i G, w, m, h}=G C p_{i G} \times g O p_{i G, w, m, h} \times \frac{g L R_{i G, w, m, h}}{100}
$$

The fuel cost is calculated by the following equations based on the load factor and the output of each generator unit. Here, $g E f_{i G, w, m, h}$ is a function that expresses the fuel consumption characteristics given by Equations (1) and (2). The relationship between the hourly average load factor of each unit and the generator output is expressed by the following equation:

$$
c F l=P r_{F l} \times \sum_{i G, w, m, h}\left(\frac{g P w_{i G, w, m, h}}{g E f_{i G}\left(g L R_{i G, w, m, h}\right)} \times d a y_{w, m}\right)
$$

Maintenance costs are generally calculated by operating hours and its unit price, regardless of the load factor of the generator.

$$
c M t=P r_{M t} \times \sum_{i G, w, m, h}\left(G C p_{i G} \times g O p_{i G, w, m, h} \times d a y_{w, m}\right)
$$

\subsection{Modeling of Conventional Load Sharing Method}

As described above, in the conventional operation method, the largest rated capacity unit $i G=L$ is operated for baseload with a $10 \%$ higher load factor than that of other units that belong to the group determined as $A G$. The load factor of each unit of $A G$ is equalized and satisfies the demand with the unit $i G=L$. The load factor of each unit satisfies the following conditions:

$$
\begin{gathered}
g L R_{L, w, m, h}=g L R_{i G \in A G, w, m, h}+10 \\
D m P w_{w, m, h}=\sum_{i G \in A G}\left(G C p_{i G} \times g O p_{i G, w, m, h} \times \frac{g L R_{i G}}{100}\right)+G C p_{L} \times g O p_{L, w, m, h} \times \frac{g L R_{L}}{100}
\end{gathered}
$$

In terms of the load factors, the margin has to be secured so that the remaining operating units except for $i G=L$ can satisfy the demand even if the largest rated capacity unit in the operating state suddenly withdraws. This constraint is expressed as follows:

$$
D m P w_{w, m, h} \leq \sum_{i G}\left(G C p_{i G} \times g O p_{i G, w, m, h}\right)-G C p_{L} \times g O p_{L, w, m, h}
$$

\subsection{Modeling of Optimal Load Sharing}

As shown in Equations (1) and (2), the relationship between the load factor and the efficiency of the generator is non-linear. Therefore, this study discretizes the values of efficiency in units of $1 \%$ of load factor to handle it using the MIP. 
According to the proposed method of this study, each unit is modeled to be able to take an arbitrary load factor $p t$. The load factor is expressed by the following constraint with the assumed minimum load factor for DGs as Bpt:

$$
B p t \leq p t \leq 100 \text { or } p t=0(p t \text { as integer })
$$

As shown in Figure 2, in this method, the values of efficiency depending on the load factor are prepared as parameters based on Equations (1) and (2) beforehand. They correspond to $g O p_{i G, p t, w, m, h}$, which takes 0 or 1 as a binary variable in the optimization.

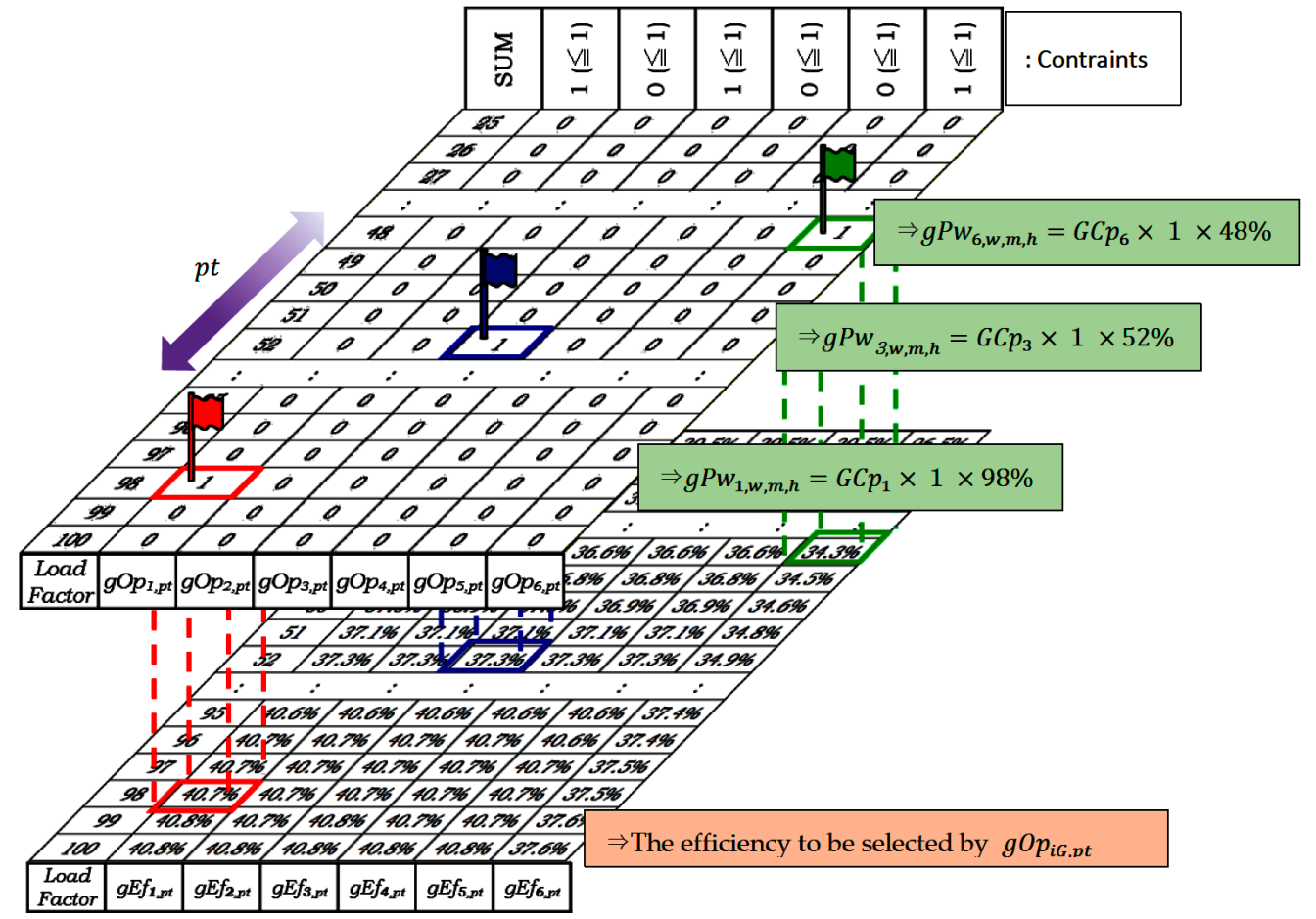

Figure 2. The example of selection the parameter of efficiency for each discretized values of load factor.

Since there is only one $g O p_{i G, p t, w, m, h}$ at each time, the following constraints are required:

$$
\sum_{p t} g O p_{i G, p t, w, m, h} \leq 1
$$

The amount of power output for each selected unit needs to exceed the demand, and the selection of the solution of optimization in the range of $p t$ for each unit is carried out with integration by binary variables $g O p_{i G, p t, w, m, h}$. In addition, fuel consumption is also calculated with the power output and the parameters of the efficiency:

$$
\begin{gathered}
D m P w_{w, m, h} \leq \sum_{i G, p t}\left\{G C p_{i G} \times g O p_{i G, w, m, h} \times \frac{p t}{100}\right\} \\
c F l=P r_{F l} \times \sum_{i G, p t, w, m, h}\left(\frac{G C p_{i G} \times p t}{100 g E f_{i G}(p t)} \times g O p_{i G, p t, w, m, h} \times d a y_{w, m}\right)
\end{gathered}
$$

The method to handle the non-linear function by the MIP is described above. By making a parameter table beforehand, the high-precision approximation of non-linear functions is realized with MIP without a larger resource of computation. In addition, this method can be applied even if the parameters are unrelated to each other, although all parameters are related through a function in this study. Therefore, this method has 
wide applicability not only for the non-linear function but also for more complicated data processing.

The constraint for resilience is also the same as the conventional method to keep a large enough margin as the preparation for sudden withdraws of unit $i G=L$ :

$$
D m P w_{w, m, h} \leq \sum_{i G}\left(G C p_{i G} \times \sum_{p t} g O p_{i G, p t, w, m, h}\right)-G C p_{L} \times \sum_{p t} g O p_{L, p t, w, m, h}
$$

Regarding Equation (12), the amount of generators output does not match the demand because the load factor is given in $1 \%$ increments of the rated capacity. This deviation is rearranged by the unit $i G=L$ operating in the mode of the baseload. This output is adjusted to match the power supply and the demand.

\section{Simulation Results and Discussion}

\subsection{Micro Grid Power Demand and Generator Assumptions}

This study assumes an independent MG such as a remote island with an annual power consumption of around 10,000 MWh. In Japan, it is similar in size to Yonaguni Island in the Okinawa region [1]. Therefore, the actual situation on the island, houses, offices, retail stores, etc., are located on the island, and the total floor area is assumed as shown in Table 2.

Table 2. The floor space according to the type of buildings.

\begin{tabular}{cc}
\hline Building Type & Floor Space $\left[\mathbf{m}^{2}\right]$ \\
\hline Offices & 2000 \\
Stores & 3000 \\
Clinics & 2100 \\
Residences and Hostels & 40,000 \\
\hline Total & 47,100 \\
\hline
\end{tabular}

The approximate scale is 20 small offices, 30 retail stores, 7 clinics, and 400 residences and guesthouses.

The power demand was calculated by multiplying the typical basic unit $\left[\mathrm{kWh} / \mathrm{m}^{2} \mathrm{~h}\right]$ of the Okinawa region with each floor area of the buildings [29]. As an example, Figure 3 shows the hourly load pattern for weekdays of average values for summer, mid-season, and winter. The annual maximum demand is $1965 \mathrm{~kW}$, while the minimum value is $655 \mathrm{~kW}$.

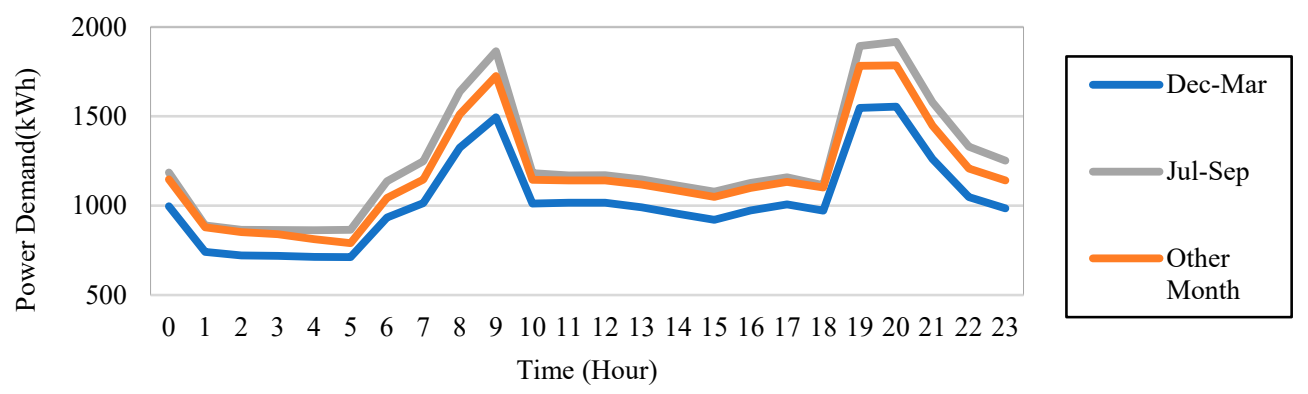

Figure 3. The power demand pattern for three seasons.

As the assumption for the existing medium-speed DGs, a total of 5 units (DG1-5) consisting of $G C p_{1,2}=550 \mathrm{~kW}$ (2 units) and $G C p_{3,4,5}=950 \mathrm{~kW}$ (3 units) are there. It is assumed that one high-speed DG (DG6) is combined and operated together. The generating capacity of the high-speed DG, GCp $p_{6}$, is analyzed in the range of $200 \mathrm{~kW}$ to $800 \mathrm{~kW}$ with an increment of $100 \mathrm{~kW}$.

The parameter $\eta$. in Equation (1) is assumed as follows. The units of $i G=2,4$, and 5 are slightly less efficient than the units of $i G=1$ and 3 . Considering this setting, the maximum capacity unit that is always in operation is $i G .=3$ for the baseload unit: 


$$
\begin{aligned}
& \eta_{1}=\eta_{3}=0 \\
& \eta_{2}=\eta_{4}=0.005 \\
& \eta_{5}=0.01
\end{aligned}
$$

The fuel for the generator is assumed to be heavy oil (Similar to MDO: Marine Diesel Oil), and the unit price per calorific value is $P r_{F l}=7.14$ [JPY $/ \mathrm{kWh}$ ] according to the actual data of Okinawa Electric Power. The maintenance unit price $\operatorname{Pr}_{M t}[\mathrm{JPY} / \mathrm{kWh}$ ] tends to differ depending on the rotation speed and the capacity of the generator as shown in Table 3.

Table 3. The maintenance cost for generators.

\begin{tabular}{rccc}
\hline Engine Type & $i G$ & $G C p_{i G}[\mathbf{k W}]$ & $\boldsymbol{P r}_{\boldsymbol{M t}}[\mathrm{JPY} / \mathbf{k W h}]$ \\
\hline \multirow{2}{*}{ Middle speed } & 1,2 & 550 & 2.2 \\
\cline { 2 - 4 } & $3,4,5$ & 950 & 2.0 \\
\hline \multirow{2}{*}{ High Speed } & \multirow{2}{*}{6} & $\leq 500$ & 2.5 \\
\cline { 2 - 4 } & & $\geq 501$ & 2.4 \\
\hline
\end{tabular}

\subsection{Case Setting}

Table 4 shows the case settings for the comparison. Case 0 is a reference case where only the medium-speed units are operated using the conventional method. Case 1 is a case where only medium-speed DGs are operated with the optimized method which this study proposes. Based on the operation of only medium-speed units, the improvement effect of only optimizing the load sharing can be evaluated by comparing with the conventional method as the first step. Case 2 and Case 3 are cases in which a high-speed DG is added to the medium-speed units. The evaluation of the effect of adding one high-speed DG with the conventional method is the second step, and finally, the effect of the optimized operation method with a high-speed generator is evaluated.

Table 4. Case settings.

\begin{tabular}{cccc}
\hline Case & Operation & $\begin{array}{c}\text { Medium-Speed DG } \\
\text { (Units) }\end{array}$ & $\begin{array}{c}\text { High-Speed DG } \\
\text { (Units) }\end{array}$ \\
\hline Case 0 & Conventional & 5 & 0 \\
Case 1 & Optimized & 5 & 0 \\
Case 2 & Conventional & 5 & 1 \\
Case 3 & Optimized & 5 & 1 \\
\hline
\end{tabular}

\subsection{Example Results with Only Medium-Speed Diesel Generators}

\subsubsection{Conventional Operation (Case 0)}

Case 0 provides the reference result for the operation of five medium-speed DGs corresponding to the assumed demand at the lowest cost in a conventional way. The load sharing of each unit is determined by Equations (7) to (9). The DG3 which has the largest rated capacity and the highest efficiency is the unit that is always operated due to baseload operation. Table 5 shows the assignment of the units for each range covering $D m P w$ from 655 to $1965 \mathrm{~kW}$ that considers the selection of generators to minimize the operating cost. Figure 4 shows the load sharing pattern from the minimum to the maximum demand throughout the year.

As the results of this case, Table 6 shows the annual operating hours of each mediumspeed DG, the total and average of the lower-load operation hours when the load factor is less than $50 \%$. It indicates that the ratio of lower-load operation of the smaller-capacity units is particularly remarkable. 
Table 5. The unit selection of the five units of medium-speed DGs operated by the conventional load sharing method.

\begin{tabular}{cccccccc}
\hline $\begin{array}{c}\text { Operation } \\
\text { Pattern }\end{array}$ & $\mathbf{D m P w}[\mathbf{k W}]$ & $g O p_{1}$ & $g O p_{2}$ & $g O p_{3}$ & $g O p_{4}$ & $g O p_{5}$ & $\begin{array}{c}\text { Supply } \\
\text { Ability [kW] }\end{array}$ \\
\hline 1 & $1900 \sim 2050$ & 1 & 1 & 1 & 1 & 0 & 3000 \\
2 & $1500 \sim 1900$ & 0 & 0 & 1 & 1 & 1 & 2850 \\
3 & $1100 \sim 1500$ & 1 & 0 & 1 & 1 & 0 & 2450 \\
4 & $950 \sim 1100$ & 1 & 1 & 1 & 0 & 0 & 2050 \\
5 & $550 \sim 950$ & 0 & 0 & 1 & 1 & 0 & 1900 \\
\hline
\end{tabular}

Note: 0 for not selected, 1 for selected.

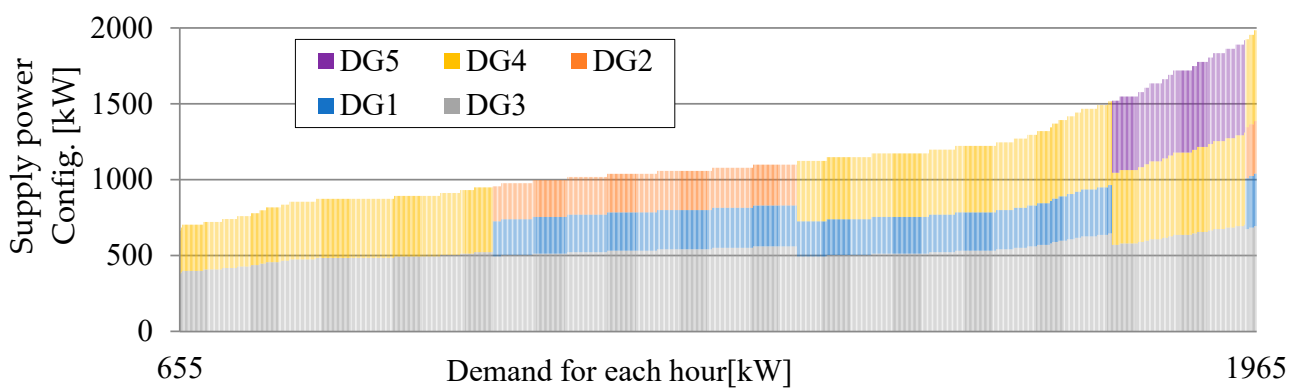

Figure 4. The load sharing pattern of the medium-speed DGs operated by the conventional load sharing method.

Table 6. The operation configuration of the five units of medium-speed DGs operated by the conventional load sharing method.

\begin{tabular}{cccc}
\hline$i G$ & $\begin{array}{c}\text { Annual } \\
\text { Operation [h] }\end{array}$ & $\begin{array}{c}\text { Annual Operation, Less } \\
\text { than } \mathbf{5 0 \%} \text { load [h] }\end{array}$ & Average Load Factor \\
\hline $\mathbf{1} \sim \mathbf{2}$ & 7544 & 6634 & $46.8 \%$ \\
$\mathbf{3} \sim \mathbf{5}$ & 16,604 & 5798 & $51.8 \%$ \\
\hline
\end{tabular}

\subsubsection{Optimal Operation Case (Case 1)}

Figure 5 shows the load sharing pattern when using the optimized load sharing method for the operation of five medium-speed DGs. Although the overall configuration of the units to be operated tends to be similar to that of the conventional method, the priorities of DGs are changed among units for some demand values. In contrast with Case 0 , the units in operation are prioritized according to their performance, and the units with higher efficiency are operated with higher load factors. Compared to Case 0 , the annual operating cost is reduced by $1.2 \%$, which improves the economic effect.

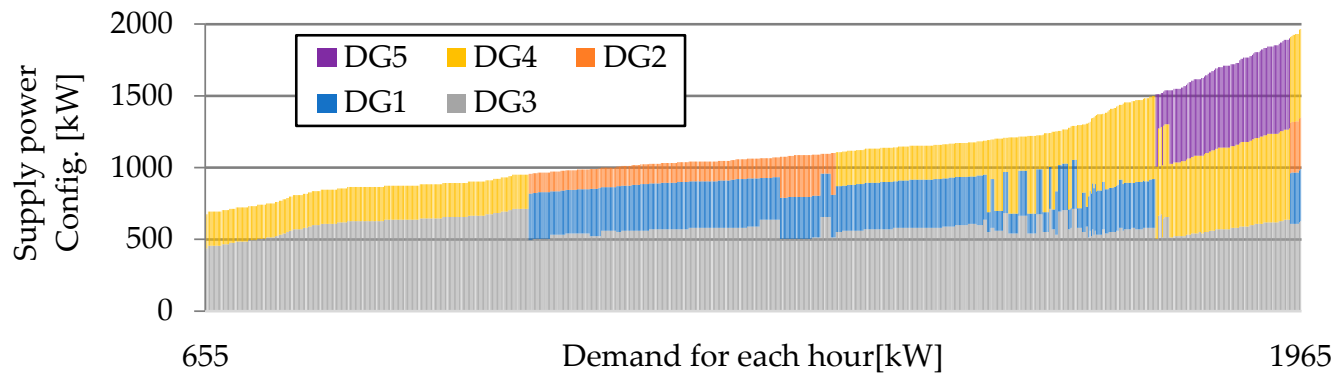

Figure 5. The load sharing pattern of the medium-speed DGs operated by the optimized load sharing method. 


\subsection{The Results of Operation with Additional High-Speed DG}

\subsubsection{Conventional Operation (Case 2)}

Figure 6 shows the cost reduction effect of Case 2 compared to Case 0 , in which one high-speed DG is combined with five medium-speed DGs while the conventional control method remains. The high-speed DG's capacity is changed from $200 \mathrm{~kW}$ to $800 \mathrm{~kW}$ to investigate the effect of capacity.

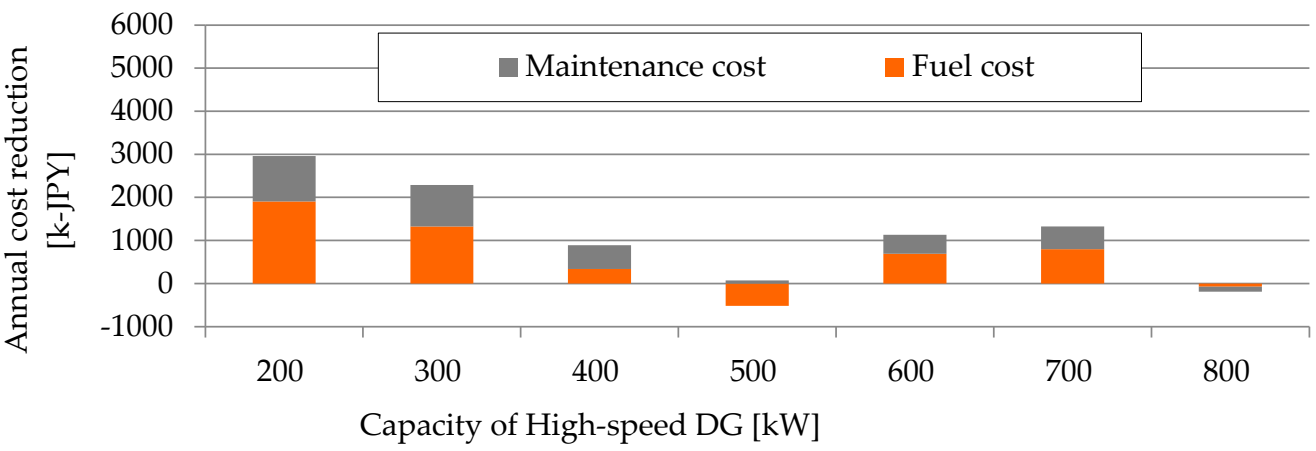

Figure 6. The annual cost reduction effect of operation when connecting a high-speed DG under the conventional method.

As an example, Table 7 shows the selection of units in cases of each capacity of the high-speed DGs is $200 \mathrm{~kW}, 500 \mathrm{~kW}$, and $800 \mathrm{~kW}$, and Figure 7 shows their load sharing patterns corresponding to the demand.

Table 7. The unit selection of the five units of medium-speed with one unit of high-speed DGs operated by the conventional load sharing method.

\begin{tabular}{|c|c|c|c|c|c|c|c|c|}
\hline Operation Pattern & $D m P w[k W]$ & $g O p_{1}$ & $g O p_{2}$ & $g O p_{3}$ & $g O p_{4}$ & $g O p_{5}$ & $g O p_{6}$ & Supply Ability [kW] \\
\hline \multicolumn{9}{|c|}{ (a) The 5 units of medium-speed $+200 \mathrm{~kW}$ the high-speed DG } \\
\hline 1 & $1900 \sim 2050$ & 1 & 1 & 1 & 1 & 0 & 0 & 3000 \\
\hline 2 & $1700 \sim 1900$ & 0 & 0 & 1 & 1 & 1 & 0 & 2850 \\
\hline 3 & $1500 \sim 1700$ & 1 & 0 & 1 & 1 & 0 & 1 & 2650 \\
\hline 4 & $1300 \sim 1500$ & 1 & 0 & 1 & 1 & 0 & 0 & 2450 \\
\hline 5 & $1150 \sim 1300$ & 1 & 1 & 1 & 0 & 0 & 1 & 2250 \\
\hline 6 & $1100 \sim 1150$ & 0 & 0 & 1 & 1 & 0 & 1 & 2100 \\
\hline 7 & $950 \sim 1100$ & 1 & 1 & 1 & 0 & 0 & 0 & 2050 \\
\hline 8 & $750 \sim 950$ & 0 & 0 & 1 & 1 & 0 & 0 & 1900 \\
\hline 9 & $550 \sim 750$ & 1 & 0 & 1 & 0 & 0 & 1 & 1700 \\
\hline \multicolumn{9}{|c|}{ (b) The 5 units of medium-speed $+500 \mathrm{~kW}$ the high-speed DG } \\
\hline 1 & $2000 \sim 2050$ & 1 & 1 & 1 & 1 & 0 & 0 & 3000 \\
\hline 2 & 1900 2000 & 1 & 0 & 1 & 1 & 0 & 1 & 2950 \\
\hline 3 & $1600 \sim 1900$ & 0 & 0 & 1 & 1 & 1 & 0 & 2850 \\
\hline 4 & $1500 \sim 1600$ & 1 & 1 & 1 & 0 & 0 & 1 & 2550 \\
\hline 5 & $1450 \sim 1500$ & 1 & 0 & 1 & 1 & 0 & 0 & 2450 \\
\hline 6 & $1100 \sim 1450$ & 0 & 0 & 1 & 1 & 0 & 1 & 2400 \\
\hline 7 & $1050 \sim 1100$ & 1 & 1 & 1 & 0 & 0 & 0 & 2050 \\
\hline 8 & $1050 \sim 1050$ & 1 & 0 & 1 & 0 & 0 & 1 & 2000 \\
\hline 9 & $550 \sim 950$ & 0 & 0 & 1 & 1 & 0 & 0 & 1900 \\
\hline \multicolumn{9}{|c|}{ (c) The 5 units of medium-speed $+800 \mathrm{~kW}$ the high-speed DG } \\
\hline 1 & 1900 2050 & 1 & 1 & 1 & 1 & 0 & 0 & 3000 \\
\hline 2 & $1750 \sim 1900$ & 0 & 0 & 1 & 1 & 1 & 0 & 2850 \\
\hline 3 & $1500 \sim 1750$ & 0 & 0 & 1 & 1 & 0 & 1 & 2700 \\
\hline 4 & $1350 \sim 1500$ & 1 & 0 & 1 & 1 & 0 & 0 & 2450 \\
\hline 5 & $1100 \sim 1350$ & 1 & 0 & 1 & 0 & 0 & 1 & 2300 \\
\hline 6 & $950 \sim 1100$ & 1 & 1 & 1 & 0 & 0 & 0 & 2050 \\
\hline 7 & $800 \sim 950$ & 0 & 0 & 1 & 1 & 0 & 0 & 1900 \\
\hline 8 & $550 \sim 800$ & 0 & 0 & 1 & 0 & 0 & 1 & 1750 \\
\hline
\end{tabular}

Note: 0 for not selected, 1 for selected. 


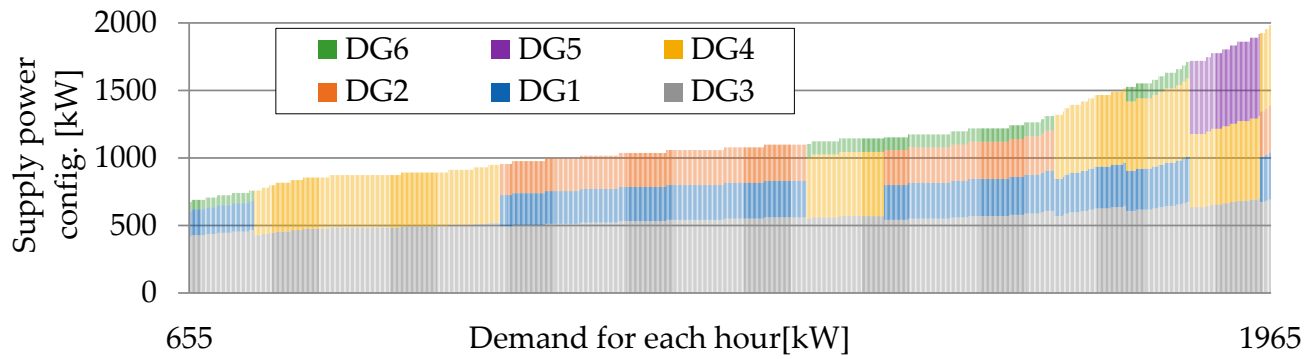

(a)

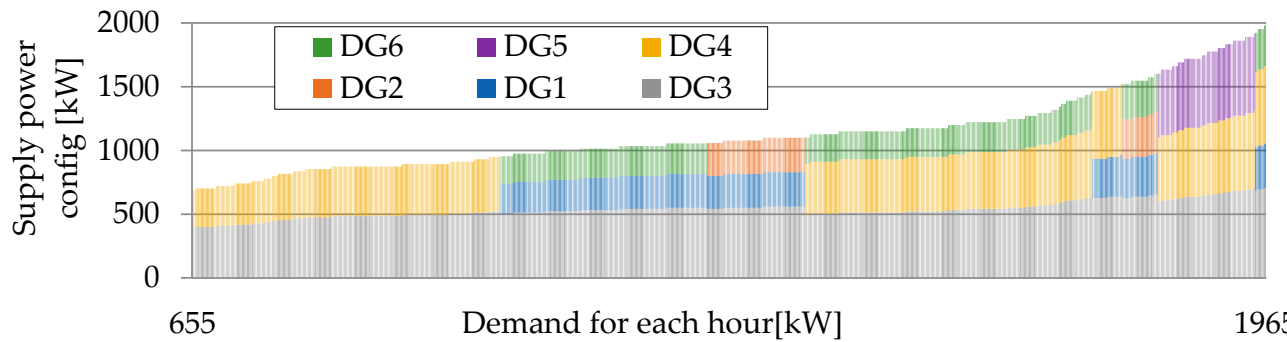

(b)

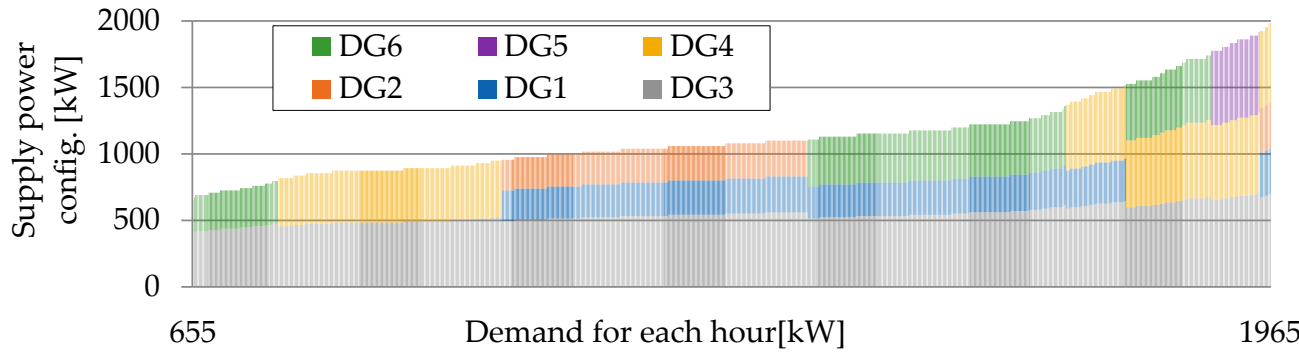

(c)

Figure 7. The load sharing pattern of the five units of medium-speed with one unit of high-speed DGs operated by the conventional load sharing method. (a) The five units of medium-speed $+200 \mathrm{Kw}$ the high-speed DG. (b) The five units of medium-speed + $500 \mathrm{Kw}$ the high-speed DG. (c) The five units of medium-speed $+800 \mathrm{Kw}$ the high-speed DG [Kw].

Even if the capacity of the combined high-speed DG is changed, the unit configuration seems to have a similar tendency for these cases. On the other hand, as shown in Figure 5, the economic effect varies greatly depending on the generator capacity of the added highspeed DG. As shown in Equations (1) and (2), the high-speed DGs are basically less efficient than the medium-speed DGs in the same output band. It is the reason why there is no improvement when the capacities are $500 \mathrm{~kW}$ and $800 \mathrm{~kW}$, which are close to the existing medium-speed DGs' capacities. The figure also shows that the economic effect increases when the capacity of the additional high-speed DG is enough small. When the required output is small and the existing medium-speed DG would be operated in a lower efficiency range, such a high-speed DG is operated in a higher efficiency range.

\subsubsection{Optimal Operation Case (Case 3)}

Figure 8 shows the load sharing patterns of the example cases installing the high-speed DG with the optimized method when the capacity of the high-speed DG is changed to $200 \mathrm{Kw}, 500 \mathrm{Kw}$, and $800 \mathrm{Kw}$. The load sharing of the operating units has a significantly different configuration compared to the results of the conventional method shown in Figures 4 and 7 . 


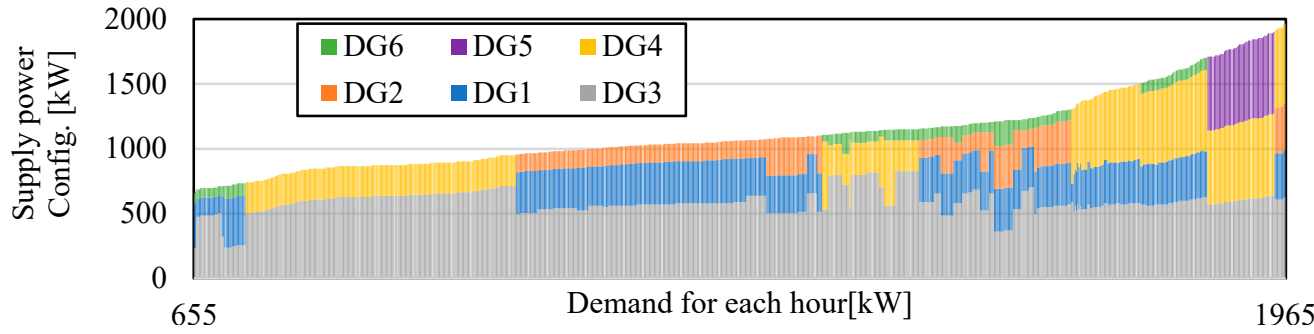

(a)

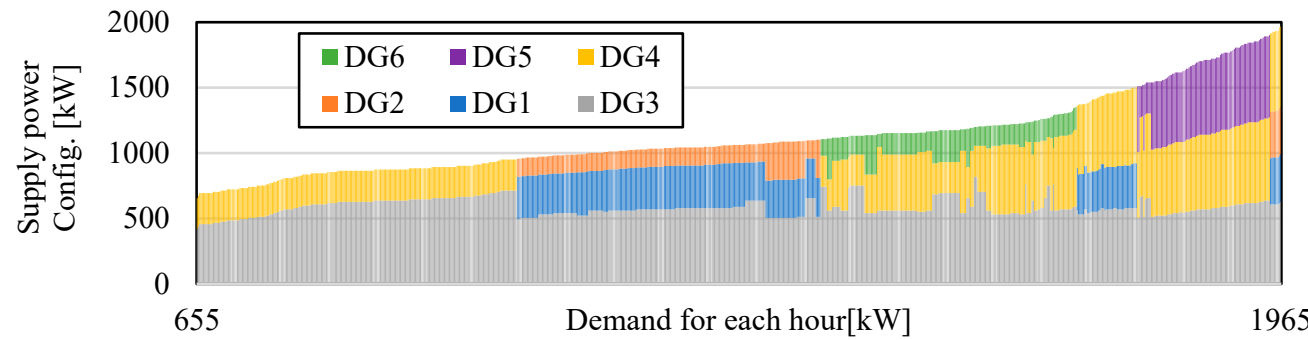

(b)

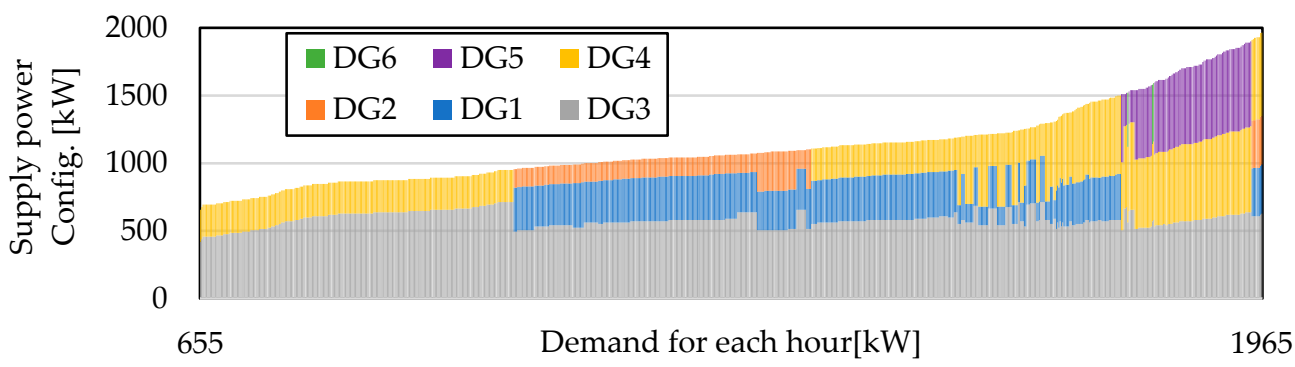

(c)

Figure 8. The load sharing pattern of the five units of medium-speed with one unit of high-speed DGs operated by the optimized load sharing method. (a) The five units of medium-speed $+200 \mathrm{~kW}$ the high-speed DG. (b) The five units of medium-speed $+500 \mathrm{~kW}$ the high-speed DG. (c) The five units of medium-speed $+800 \mathrm{~kW}$ the high-speed DG.

Figure 9 shows the annual operating hours of each unit and the ratio of the lower-load operating hours for Case 0, Case 1, and Case 3. In terms of operating hours for the highspeed DG in Case 3, they decrease as the capacity approaches that of the medium-speed DG and $500 \mathrm{Kw}$ and $800 \mathrm{Kw}$ are rarely operated. The reason for this is that it is impossible to replace the medium-speed DGs with a lower-efficiency but a higher-speed DG in such a situation. In terms of operation hours for the medium-speed DG, the change between Case 1, Case 3, and Case 0 is small while the optimized load sharing methods are installed. In contrast, in terms of the ratio of lower-load operation, that of the medium-speed is greatly suppressed, although that of the high-speed DG remains high for all capacities. The ratio of lower-load operation for the larger capacity of the medium-speed DG is greatly reduced, especially in the case of $200 \mathrm{Kw}$ and $700 \mathrm{Kw}$ of the high-speed DG, which implies that the optimized load sharing is successful in operating the medium-speed DGs with higher load factors.

\subsubsection{Effect of Adding a High-Speed DG}

Figure 10 shows the annual cost reduction effect of Case 3, installing the additional high-speed DG with the optimized load sharing method, compared to the annual operating cost of Case 0, which operates only medium-speed DGs with the conventional method. $\mathrm{CO}_{2}$ emissions are reduced in proportion to the fuel reduction. 


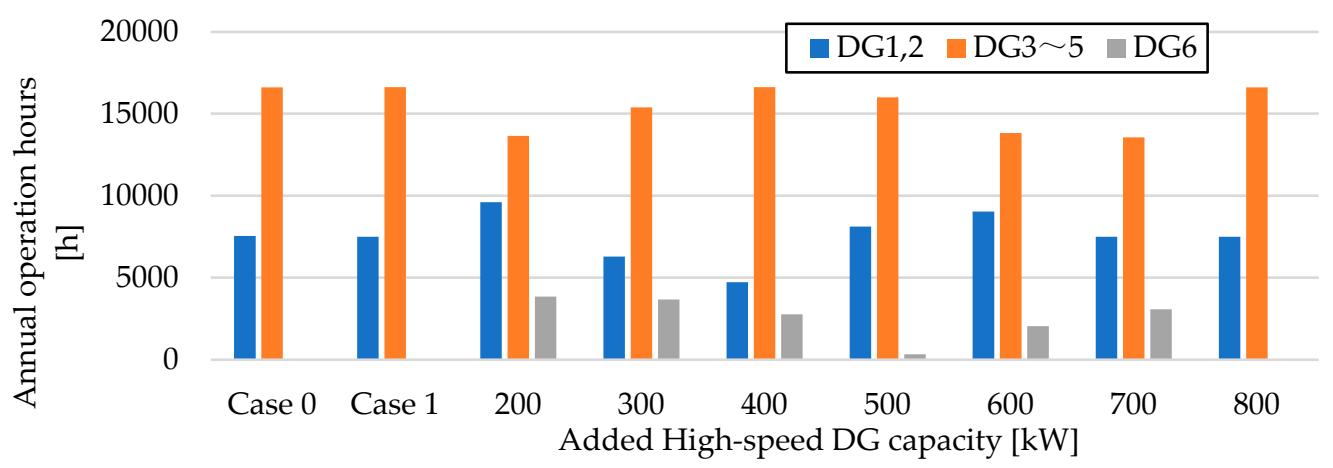

(a)

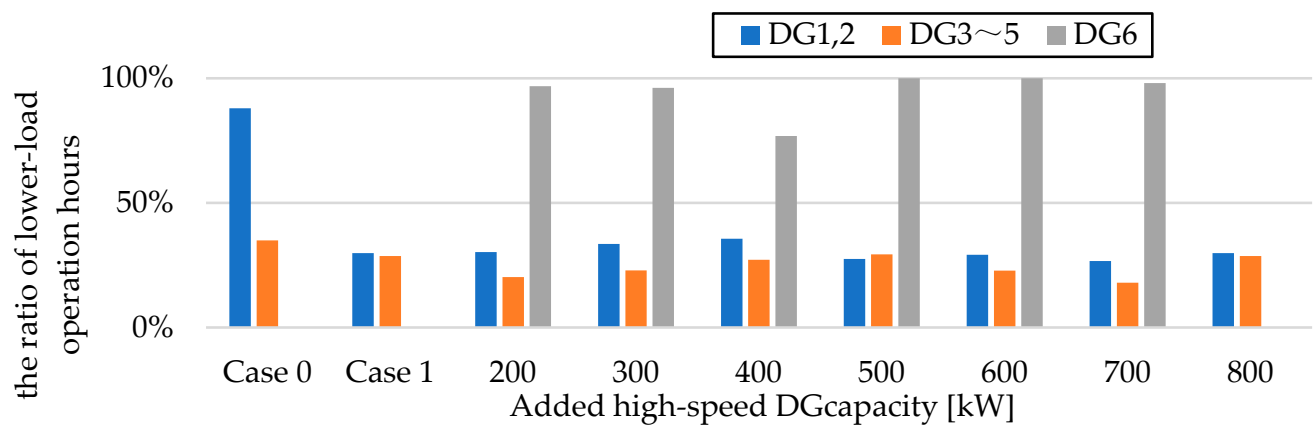

(b)

Figure 9. The annual operation hours and the ratio of low load operation hours of Case 0, Case 1, and Case 3: (a) Annual operation hours; (b) The ratio of low load operation hours for a load factor less than $50 \%$.

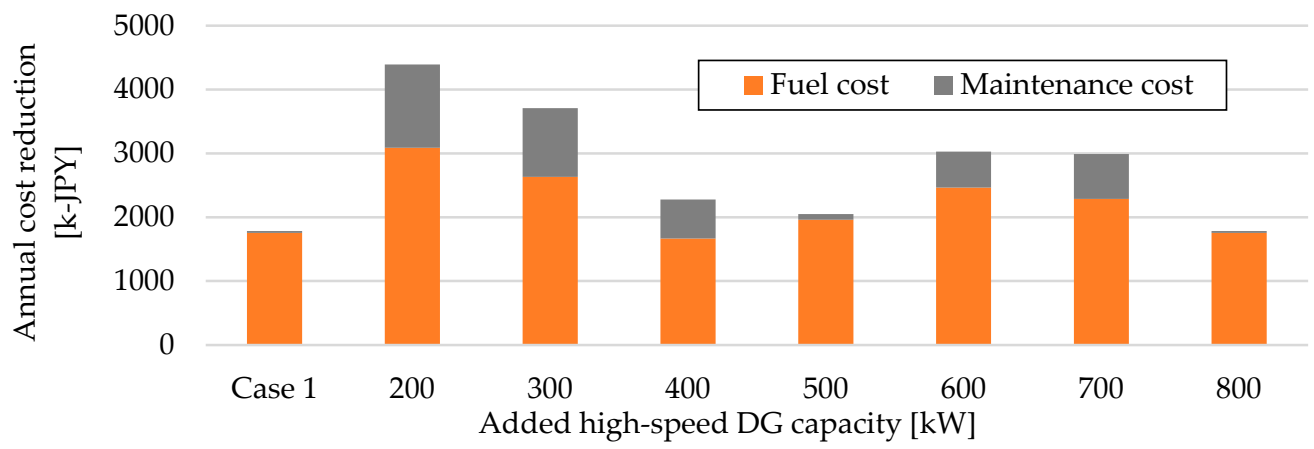

Figure 10. The annual cost reduction effect of Case 1 and Case 3 in comparison with Case 0.

In Case 3 with the optimized load sharing method, the results are quite different from those of Case 2 controlled by the conventional method. The effect of reducing operating costs can be obtained in all capacity cases with a high-speed DG added. When the capacity of the high-speed DG is $800 \mathrm{~kW}$, the effect is almost the same as that of Case 1 due to the limited operation. The tendency of the effect depending on the rated capacity of the high-speed DG is similar to Case 2. The biggest cost reduction effect can be expected in the case where the capacity is $200 \mathrm{~kW}$ : these are $1.9 \%$ compared to Case 0 and $1.1 \%$ compared to Case 1. It indicates that the effect becomes bigger with the differences of the rated capacities between the high-speed and the medium-speed.

From the viewpoint of the investment recovery, assuming that the price of the highspeed DG is USD 150/kW [30] and the useful life of the equipment is 15 years, the investment recovery can be expected only in the case of the high-speed DG of $200 \mathrm{~kW}$ in Case 2 without optimization. In contrast, in the optimized cases, the investment recovery can be expected for the addition of the high-speed DGs from $200 \mathrm{~kW}$ to $700 \mathrm{~kW}$. It should be noted 
that the effect of operating cost reduction can be also expected even when applying only the optimization method without any additional power supply resource as in Case 1.

\section{Conclusions}

\subsection{Results Analysis}

According to the result of this study, when installing an additional generator, the economic effect varies greatly depending on the rated capacity of the added high-speed DG. In the case where the difference between the capacity of the additional DG and those of existing DGs is big, the effect tends to be great. The reason is that a smaller high-speed DG can be operated in the higher efficiency range even when the required output capacity is small.

With the conventional control method, the effect of operating cost reduction may not be obtained depending on the capacity. In contrast, the effect would be expected regardless of the capacity of the additional high-speed DG by installing the new method of optimizing the load sharing. From the viewpoint of the change of the operating hours of the mediumspeed DG by installing the new method, the low-efficiency range is decreased, and the high-efficiency range is increased. The reason is that the new method is performed so that the load factor of the high-speed DG shall be suppressed to operate the medium-speed DGs in the high-efficiency range.

\subsection{Evaluation for the Optimization of Load Sharing}

This study evaluated the economic effect of the new method of optimizing load sharing. This optimization method focuses on the load factor of DG and handles nonlinear functions such as the performance curve of the reciprocating engine generator. The situation to evaluate the effect is not only for the current state where the medium-speed DGs are operated regularly in the range but also for the addition of a high-speed DG, which is one of the solutions for resilience issues for independent MGs.

The results indicate that the economic effect is achievable when adding one high-speed DG whose capacity is smaller than the existing ones. In addition, the effect is increased by applying the optimized method. Generally, the range of appropriate capacity for additional generators to obtain an economic effect corresponding to the target demand configuration is narrow. However, this study suggests the possibility of expanding the range by this method. In other words, the flexibility for the capacity proportion between the demand and the generators is increased by this method.

Compared to the medium-speed DGs, the high-speed DGs have lower-rated efficiency and higher maintenance unit prices. Nevertheless, this study revealed that the optimization of load sharing control can improve the economic effect by combining it with an independent MG for regular usage. From this result, it was suggested that the high-speed DGs, which are generally recognized as relatively difficult to use in a regular operation for long-life power plants, are expected to play a role from the viewpoint of the MG's resilience issue. In other words, it is systematically advantageous to mix different capacities of the high-speed DGs instead of configuring the generators with only one type of medium-speed DG.

Furthermore, the method of optimization of the load sharing proposed in this study performs an appropriate load sharing to reduce the operation cost and has also the advantage of expanding the range of generator selection compared to the conventional load sharing method. It can be emphasized that this method will contribute to improving the economy of power plants in MGs. These points are very important, especially for independent MG since the demand pattern is gradually changed as time goes by. This result is useful not only for the existing power supply business in remote areas but also for the development in off-the-grid areas. 
Author Contributions: Conceptualization, methodology, software, validation, formal analysis, investigation, resources, data curation, and writing—original draft preparation, S.Y.; writing-review and editing, S.Y. and A.A.; visualization, S.Y.; supervision, A.A.; project administration, A.A. All authors have read and agreed to the published version of the manuscript.

Funding: This research received no external funding.

Institutional Review Board Statement: Not applicable.

Informed Consent Statement: Not applicable.

Conflicts of Interest: The authors declare no conflict of interest.

\section{Nomenclature}

\begin{tabular}{|c|c|c|}
\hline \multicolumn{3}{|l|}{ Index } \\
\hline$A G$ & Group of Generator units $i G$ except $i G=L$. & \\
\hline$h$ & Hours & 1 to 24 \\
\hline$i G$ & Generator units & 1 to 6 \\
\hline$L$ & The unit number of the maximum capacity & \\
\hline$m$ & Month & 1 to 12 \\
\hline$p t$ & Load factor [\%], an integer from & Bpt to 100 \\
\hline$w$ & Day types & $\begin{array}{l}\text { Weekday, Saturday, } \\
\text { and Holiday }\end{array}$ \\
\hline \multicolumn{3}{|c|}{ Variables and parameters } \\
\hline Bpt & Minimum operating load factor [\%] & \\
\hline$c F l$ & Annual fuel cost $[J P Y]$ & \\
\hline$c M t$ & Maintenance cost [JPY] & \\
\hline$c O p$ & Annual operating cost [JPY] & \\
\hline$d a y_{w, m}$ & $\begin{array}{l}\text { Number of days for each day type of the } \\
\text { target month }\end{array}$ & \\
\hline$D m P w_{w, m, h}$ & Power demand $[\mathrm{kW}]$ & \\
\hline$G C p_{i G}$ & $\begin{array}{l}\text { Rated output of each power generation facility } \\
i G[\mathrm{~kW}]\end{array}$ & \\
\hline$g E f_{i G}(x)$ & $\begin{array}{l}\text { The power generation efficiency of each power } \\
\text { generation facility with the load factor } x[\%] \text { as } \\
\text { a variable }\end{array}$ & \\
\hline$g L R_{i G, w, m, h}$ & $\begin{array}{l}\text { Load factor of each power generation facility } \\
i G[\%]\end{array}$ & \\
\hline$g O p_{i G, w, m, h}$ & Operating state at each time as binary & \\
\hline$g P w_{i G, w, m, h}$ & Power generation output $[\mathrm{kW}]$ & \\
\hline $\operatorname{Pr}_{F l}$ & Fuel unit price per calorifique value [JPY/kW-h] & \\
\hline $\operatorname{Pr}_{M t}$ & Maintenance unit price [JPY/kWh] & \\
\hline$x$ & A variable of function & \\
\hline$\eta$ & $\begin{array}{l}\text { The uneven performance of the } \\
\text { medium-speed DGs }\end{array}$ & \\
\hline Definitions & & \\
\hline loperation & operation in load factor less than 50 percent & \\
\hline
\end{tabular}

\section{References}

1. Landbrain Co., Ltd. Survey Report on the Potential of All-Energy Renewable Energy Projects on Small Remote Islands Mar. 2014 Available online: https://www.pref.okinawa.jp/site/shoko/seisaku/kiban/syoukiboritoukoubo/documents/h25houkokusyo1 4.pdf (accessed on 25 October 2021).

2. Sasaki, H.; Seino, M.; Hashimoto, N.; Sakata, I. Off-Grid Electrification Scenarios for Rural Electrification in Myanmar. 2018. Available online: https://energypedia.info/wiki/Publication_-_Off-Grid_Electrification_Scenarios_for_Rural_Electrification_ in_Myanmar (accessed on 7 October 2021).

3. Dulău, L.I.; Bică, D. Optimization of generation cost in a microgrid. Procedia Manuf. 2018, 22, 703-708. [CrossRef]

4. He, L.; Lu, Z.; Pan, L.; Zhao, H.; Li, X.; Zhang, J. Optimal Economic and Emission Dispatch of a Microgrid with a Combined Heat and Power System. Energies 2019, 12, 604. [CrossRef]

5. Togawa, T.; Dou, Y.; Oba, M.; Nemoto, K.; Nakumura, S.; Fujii, M. Desing and Standards for Distributed Energy System in the Inter-Mountainous Area. J. Jpn. Soc. Civ. Eng. Ser. G Environ. Res. 2017, 73, I_107-I_119. [CrossRef] 
6. Kannengießer, T.; Hoffmann, M.; Kotzur, L.; Stenzel, P.; Schuetz, F.; Peters, K.; Nykamp, S.; Stolten, D.; Robinius, M. Reducing Computational Load for Mixed Integer Linear Programming: An Example for a District and an Island Energy System. Energies 2019, 12, 2825. [CrossRef]

7. Gildenhuys, T.; Zhang, L.; Ye, X.; Xia, X. Optimization of the Operational Cost and Environmental Impact of a Multi-Microgrid System. Energy Procedia 2019, 158, 3827-3832. [CrossRef]

8. Ito, K.; Yokoyama, R. A Planning Method for Optimal Operation of Cogeneration Systems: Part 1-Methodological Study. J. Trans. Soc. Heat. Air-Cond. Sanit. Eng. Jpn. 1990, 15, 59-67. (In Japanese)

9. Chiba, R.; Tanahashi, Y.; Nishiwaki, O.; Tanaka, H. Study on Optimization of Control Parameters for Generator Operation with Multiple Units in a Combined Generator System. J. Trans. Soc. Heat. Air-Cond. Sanit. Eng. Jpn. 2018, 43, 11-19. (In Japanese)

10. Pang, C.; Mohsenzadeh, A.; Haghifam, M. Determining optimal forming of flexible microgrids in the presenceof demand response in smart distribution systems. IEEE Syst. J. 2017, 12, 3315-3323.

11. Ghiasi, M.; Niknam, T.; Dehghani, M.; Siano, P.; Alhelou, H.H.; Al-Hinai, A. Optimal Multi-Operation Energy Management in Smart Microgrids in the Presence of RESs Based on Multi-Objective Improved DE Algorithm: Cost-Emission Based Optimization. Appl. Sci. 2021, 11, 3661. [CrossRef]

12. Koguma, Y.; Inamura, A. Mathematical Optimization Model and Algorithm for Energy System Configuration and Operation J. IHI Technol. 2019, 59, 24-35. (In Japanese)

13. Shinji, T.; Kumagai, K.; Akisawa, A.; Kashiwagi, T.; Fujita, G. Study on Generator Dispatching Considering Partial Load Efficiency of GT under a Daily Load Curve in Microgrids. J. Jpn. Inst. Energy 2011, 90, 654-659. [CrossRef]

14. Watanabe, I.; Sagai, S.; Tokoro, K.; Komatsu, H.; Higo, T. Development of Demand and Supply Operation Simulator Considering the Output Fluctuation of Renewable Energy-Prototype Development of Demand and Supply Planning Function. J. Cent. Res. Inst. Electr. Power Ind. 2014, R13013, 1-19. (In Japanese)

15. Tomita, Y. Glossary 64th Theme: Economic Load Allocation (ELD). IEEJ Trans. Power Energy 2016, 136, NL7_9.

16. Japan Cogeneration Center. New Edition Cogeneration Comprehensive Manual 2003; Japan Cogeneration Center: Tokyo Japan, 2003. (In Japanese)

17. Kojima, T.; Fukuta, Y. Microgrid System for Isolated Islands. Fuji Electr. J. 2011, 84, 188-193.

18. Lavrik, A.; Zhukovskiy, Y.; Tcvetkov, P. Optimizing the Size of Autonomous Hybrid Microgrids with Regard to Load Shifting. Energies 2021, 14, 5059. [CrossRef]

19. The Chugoku Electric Power Company, Incorporated. Demonstration project of hybrid storage battery system in Oki Islands J. Inst. Electr. Install. Eng. Jpn. 2018, 38, 57-58. (In Japanese)

20. Okinawa Enetech Co., Inc. Improving Plant Efficiency by Improving the Operation of Power Plants. JICA Report. 2014. Available online: https:/ / openjicareport.jica.go.jp/pdf/12229035_02.pdf (accessed on 25 October 2021).

21. Committee Secretariat on Coordination and Demand-Supply Balance Evaluation, etc. Examination of Technical Issues and Countermeasures for Renewable Energy Main Power Source. Organization for Cross-Regional Coordination of Transmission Operators, Japan. 2020. Available online: https://www.occto.or.jp/iinkai/chouseiryoku/2020/ (accessed on 25 October 2021).

22. Mitsubishi Research Institute, Inc. Recognition of the Current Situation Regarding Power Storage Systems. Ministry of Economy, Trade and Industry. 2020. Available online: https://www.meti.go.jp/shingikai/energy_environment/storage_system/pdf/001_ 05_00.pdf (accessed on 25 October 2021).

23. Hirota, S.; Kanoh, M.; Hara, T. Lithium-ion Battery System for Smart Grid. Hitachi Chemical Technical Report 2014 No.57. Available online: https://www.mc.showadenko.com/japanese/report/057/57.pdf (accessed on 25 October 2021).

24. U.S. Environmental Protection Agency Combined Heat and Power Partnership. Catalog of CHP Technologies Section 2. Technology Characterization Reciprocating Internal Combustion Engines. 2015. Available online: http:/ /www.gossengineering. com/wp-content/uploads/2017/03/CATALOG-OF-CHP-TECHNOLOGIES.pdf (accessed on 25 October 2021).

25. Yamano, S.; Nakaya, T.; Ikegami, T.; Nakayama, M.; Akisawa, A. Optimization modeling of mixed gas engine types with different maintenance spans and costs: Case study OF CCHP to evaluate optimal gas engine operations and combination of the types. Energy 2021, 222, 119823. [CrossRef]

26. Kohler, Co. Model: 800REOZM. 2018. Available online: https://www.kohlerpower.sg/onlinecatalog/pdf/800REOZM.pdf (accessed on 25 October 2021).

27. Daihatsu Diesel Mfg. Co., Ltd. Guaranteed Fuel Consumption Curve at Site List No. PC-160610-001Z; Daihatsu Diesel Mfg. Co., Ltd.: Osaka, Japan, 2016.

28. Horii, S.; Ito, K.; Pak, P.S.; Suzuki, Y. Optimal planning of gas turbine co-generation plants based on mixed-integer linear programming. Int. J. Energy Res. 1987, 11, 507-518. [CrossRef]

29. Tomofuji, D.; Akisawa, A. Effect of Introducing Gas Engine Cogeneration in Non-Residential Building Considering Regional Characteristics-Study on Energy Saving, Securing BCP Power Supply, and Demand Response. J. Jpn. Soc. Energy Resour. 2018, 39, 1-10.

30. Generac Power Systems, Inc. White Paper Total Cost of Ownership Diesel vs. Gas Generators. 2017, p. 3. Available online: https:// gensetservices.com/wp-content/uploads/2017/11/TCO-_diesel_vs_natural_gas_generators.pdf (accessed on 25 October 2021). 